\title{
Self-microemulsifying drug delivery system for improved oral bioavailability of oleanolic acid: design and evaluation
}

This article was published in the following Dove Press journal:

International Journal of Nanomedicine

7 August 2013

Number of times this article has been viewed

\section{Rui Yang' \\ Xin Huang' \\ Jinfeng Dou ${ }^{2}$ \\ Guangxi Zhai ${ }^{2}$ \\ Lequn $\mathrm{Su}^{\prime}$}

'Pharmacy Department, Shandong Provincial Qianfoshan Hospital, Shandong University, Jinan, People's Republic of China; ${ }^{2}$ Department of Pharmaceutics, College of Pharmacy, Shandong University, Jinan, People's Republic of China
Correspondence: Lequn Su Pharmacy Department, Shandong Provincial Qianfoshan Hospital, 66 Jingshi Road, Jinan 2500 I4, People's Republic of China Email professorslq@I26.com

\begin{abstract}
Oleanolic acid is a poorly water-soluble drug with low oral bioavailability. A selfmicroemulsifying drug delivery system (SMEDDS) has been developed to enhance the solubility and oral bioavailability of oleanolic acid. The formulation design was optimized by solubility assay, compatibility tests, and pseudoternary phase diagrams. The morphology, droplet size distribution, zeta potential, viscosity, electrical conductivity, and refractive index of a SMEDDS loaded with oleanolic acid were studied in detail. Compared with oleanolic acid solution, the in vitro release of oleanolic acid from SMEDDS showed that the drug could be released in a sustained manner. A highly selective and sensitive high-performance liquid chromatographymass spectrometry method was developed for determination of oleanolic acid in rat plasma. This method was used for a pharmacokinetic study of an oleanolic acid-loaded SMEDDS compared with the conventional tablet in rats. Promisingly, a 5.07-fold increase in oral bioavailability of oleanolic acid was achieved for the SMEDDS compared with the marketed product in tablet form. Our studies illustrate the potential use of a SMEDDS for delivery of oleanolic acid via the oral route.
\end{abstract}

Keywords: oleanolic acid, self-microemulsifying drug delivery system, formulation design, in vitro release, bioavailability

\section{Introduction}

Oleanolic acid [(3ß)-3-hydroxyolean-12-en-28-oic acid], is a triterpenoid compound found widely in food, medicinal herbs, and other plants in the form of free acid or aglycones of triterpenoid saponins. ${ }^{1-3}$ In 1975, the hepatoprotective effects of oleanolic acid were first identified during the study of Swertia mileensis, a traditional herbal medicine used for hepatitis. Of the three compounds isolated from this herb, oleanolic acid was the most effective in protecting against $\mathrm{CCl}_{4}$-induced liver injury in rats. ${ }^{4}$ The hepatoprotective effects of oleanolic acid allow its use in the People's Republic of China as an over-the-counter oral drug for the treatment of human liver disorders such as acute and chronic hepatitis. ${ }^{4-6}$ A variety of other pharmacologic actions of oleanolic acid have been reported, including antihypertensive, antiatherosclerotic and antioxidant activity, ${ }^{7,8}$ cardiotonic and antidysrhythmic effects, ${ }^{9}$ immunomodulatory activity, ${ }^{10}$ and inhibitory effect on $\alpha$-glucosidase, cytochrome P450,12-o-tetradecanoylphorbol-13acetate-induced gene expression. ${ }^{11-13}$

However, the application of oleanolic acid has been limited by its poor water solubility and low bioavailability ( $0.7 \%$ in rats) after oral administration. ${ }^{14-17}$ To improve its solubility and bioavailability and increase its clinical efficacy, several approaches 
have been reported, including development of nanosuspensions ${ }^{18}$ and solid dispersions ${ }^{19}$ containing oleanolic acid.

Recently, with successful clinical use of the cyclosporine formulations Sandimmune ${ }^{\circledR}$ and Neoral ${ }^{\circledR}$ (Novartis Pharmaceuticals Corporation, East Hanover, NJ, USA), the self-microemulsifying drug delivery system (SMEDDS), an isotropic mixture of oil, surfactant, cosurfactant (or solubilizer), and drug, has attracted great interest in the pharmaceutical industry. When diluted in aqueous phases under gentle agitation or by digestive motility in the gastrointestinal tract, a SMEDDS can rapidly form an oil/water $(\mathrm{o} / \mathrm{w})$ microemulsion with a droplet size of less than $100 \mathrm{~nm}$ and have a large surface area. ${ }^{20,21}$ SMEDDS increases the oral bioavailability of a lipophilic drug by enhancing its solubility, having a small droplet size which provides a large interfacial surface area, and promoting intestinal lymphatic drug transport. $^{22,23}$ In recent decades, SMEDDSs have been reported to improve the oral absorption and bioavailability of several drugs, including oridonin, simvastatin, and silymarin. ${ }^{24-26}$ The relative bioavailability of silymarin in a SMEDDS increased dramatically by 1.88 -fold and 48.82 -fold compared with silymarin in polyethylene glycol 400 solution and suspension, respectively. ${ }^{26}$

In this study, an oleanolic acid-loaded SMEDDS was prepared, and its characteristics and release in vitro were investigated. The oral bioavailability of oleanolic acid in this SMEDDS was evaluated in rats and compared with that of commercial tablets. A sensitive high-performance liquid chromatography (HPLC)-mass spectrometry method was established for determination of oleanolic acid in rat plasma.

\section{Materials and methods Materials}

Oleanolic acid was sourced from Xieli Co, Ltd (Sichuan, People's Republic of China) with a purity of 99\%. Polyoxyethyleneglycerol triricinoleate 35 castor oil (Cremophor $\mathrm{EL}^{\circledR}$ ) was purchased from Sigma Chemical Co (St Louis, MO, USA). Polyoxyethylene octylphenyl ether and oleic acid were obtained from Kemiou Chemical Reagent Co, Ltd (Tianjin, People's Republic of China). Labrasol ${ }^{\circledR}$ (caprylocaproyl macrogol-8 glyceride) was provided by Gattefosse (Saint-Priest, France). Octyl and decyl glycerate was purchased from Heshibi Chemical Reagent Co, Ltd (Shanghai, People's Republic of China). Isopropyl myristate was obtained from Fluka Chemie AG (Buchs, Switzerland). Ethanol, Tween ${ }^{\circledR} 80$, and ethyl oleate were obtained from Guangcheng Chemical Reagent Co, Ltd (Tianjin, People's Republic of China). The reference substance of oleanolic acid and benorilate were provided by the National Institute for the Control of Pharmaceutical and Biological Products (Beijing, People's Republic of China). HPLC-grade acetonitrile and methanol were supplied by Merck (Darmstadt, Germany). Deionized water was prepared using a Milli-Q purification system from Millipore (Molsheim, France). All other chemicals were of analytical grade. Commercially available tablets (Lot 0706301) each containing $20 \mathrm{mg}$ of oleanolic acid were supplied by Jiangsu Pengyao Pharmaceutical Co (Jiangsu, People's Republic of China).

\section{Animals}

Male Sprague Dawley rats (weighing $220 \pm 10 \mathrm{~g}$, about 8 weeks of age) were supplied by the Laboratory Animal Center of Shandong University. The animals were housed individually under normal conditions with food and water ad libitum. All experimental procedures were approved by the institutional animal ethics committee and were in compliance with the National Institutes of Health Guide for Care and Use of Laboratory Animals.

\section{Solubility studies}

The solubility of oleanolic acid in different oils, surfactants, and cosurfactants was determined. An excess amount of oleanolic acid was added to $2 \mathrm{~g}$ of the selected vehicles. The resulting mixture was shaken at $60^{\circ} \mathrm{C}$ to facilitate solubilization, and then kept at $25^{\circ} \mathrm{C}$ for 48 hours, followed by centrifugation at $10,000 \mathrm{rpm}$ for 10 minutes. The supernatant was filtered through a membrane filter $(0.45 \mu \mathrm{m})$ to remove the remaining insoluble oleanolic acid. The saturated solubility of oleanolic acid was then determined using an HPLC analysis system consisting of a 515 series HPLC pump (Waters, Milford, MA, USA) and a model 500 series detector (Shimadzu Scientific Instruments Inc, Columbia, MD, USA). Oleanolic acid was separated at $210 \mathrm{~nm}$ using an ODS analytical column $(250 \mathrm{~mm} \times 4.6 \mathrm{~mm}$ ID, $5.0 \mu \mathrm{m}$, Phenomenex Inc, Torrance, CA, USA). Mobile phase was $4 \%$ acetic acid and acetonitrile, the volume ratio was 95:5, the flow rate was $1.0 \mathrm{~mL}$ per minute, the sample size was $20 \mu \mathrm{L}$, and the retention time was about 9.8 minutes.

\section{Compatibility tests}

To assess the compatibility of the system, different surfactants and oils were mixed using a magnetic stirrer at three ratios of surfactant to oil (90:10, 80:20, 70:30). Next, $0.1 \mathrm{~mL}$ of each formulation was pipetted into $10 \mathrm{~mL}$ of purified water at $37^{\circ} \mathrm{C}$, and agitated gently. Each formulation was assessed visually according to the rate of emulsification and the final appearance 
of the emulsion. ${ }^{27}$ The performance of the formulations in vitro was visually assessed following the grading system.

\section{Selection of cosurfactants}

In order to choose the optimal cosurfactant, pseudoternary phase diagrams of surfactant/cosurfactant, oil, and water were constructed using the titration method. The mixed surfactant was prepared at a fixed weight ratio $(2: 1)$ of surfactant to cosurfactant $(\mathrm{Km})$. The weight ratio of oil to mixed surfactant was varied as 9:1, 8:2, 7:3, 6:4, 5:5, 4:6, 3:7, 2:8, and 1:9, respectively. Each mixture was titrated with water and observed visually for phase clarity and flowability. The concentration of water at which turbidity-to-transparency and transparency-to-turbidity transitions occurred was derived from the weight measurements. These values were then used to determine the boundaries of the microemulsion domain. ${ }^{28,29}$

\section{Formulation optimization}

A ternary phase diagram of surfactant, cosurfactant, and oil was constructed to determine the concentration of components for the existing range of SMEDDS. First, the mixed surfactants were prepared at different $\mathrm{Km}$, which varied as 10:0, 9:1, 8:2, 7:3, 6:4, 5:5, 4:6, 3:7, 2:8, and 1:9. The mixture containing oil and mixed surfactant was then prepared with weight ratios of oil to mixed surfactant of $9: 1,8: 2,7: 3,6: 4$, $5: 5,4: 6,3: 7,2: 8$, and 1:9, respectively. Next, $0.1 \mathrm{~mL}$ of each mixture was pipetted into $10 \mathrm{~mL}$ of purified water at $37^{\circ} \mathrm{C}$ under gentle stirring. The diluted solution which appeared clear or slightly bluish was the formed microemulsion.

\section{Preparation of oleanolic acid-loaded SMEDDS}

The SMEDDS consisted of Cremophor EL, ethanol, and ethyl oleate at a weight ratio of 50:35:15. The SMEDDS was prepared by mixing the formulation components together with gentle stirring at $40^{\circ} \mathrm{C}$ for 20 minutes. Oleanolic acid was then added, and the product was stirred until clear and a transparent solution was obtained. The final concentration of oleanolic acid in the SMEDDS was $1 \%(\mathrm{w} / \mathrm{w})$. The mixture was stored at room temperature until used.

\section{Physicochemical characterization of SMEDDS}

\section{Morphologic characterization}

The oleanolic acid-loaded SMEDDS (1 mL) was diluted with distilled water $(100 \mathrm{~mL})$ to form a microemulsion. The morphology of the resulting microemulsion was observed using a transmission electron microscope (JEM-100CXII,
JEOL, Tokyo, Japan). One drop of diluted sample was deposited on a film-coated copper grid, stained with a $2 \%$ aqueous solution of phosphotungstic acid, and allowed to dry before being observed under the electron microscope.

\section{Droplet size and zeta potential determination}

The droplet size distribution was determined using a photocorrelation spectroscopy instrument (BI-200SM, Brookhaven Instruments, Holtsville, NY, USA) at $25^{\circ} \mathrm{C}$. The effect of different types of dilution medium and volume on the droplet size of the microemulsion was determined.

\section{Viscosity, electrical conductivity, and refractive index determination}

Viscosity was measured at $25^{\circ} \mathrm{C}$ using a NDJ-8S digital viscometer (Shanghai Precision and Scientific Instrument, Shanghai, People's Republic of China) with a No 1 rotor set at $60 \mathrm{rpm}$. Electrical conductivity was determined using a conductivity meter (DDS-11C, Shanghai San-Xin Instrumentation Inc, Shanghai, People's Republic of China), and the refractive index was measured with a Abbe refractometer (Shijiazhuang Optical Instrument Factory, Xiamen, People's Republic of China).

\section{In vitro release studies}

A dialysis method was used to study the release of oleanolic acid from the SMEDDS in vitro. ${ }^{25,26}$ The oleanolic acidloaded SMEDDS (diluted with release medium) was put into the dialysis bag (molecular weight cutoff 10,000, Spectrum Medium Industries Inc, Peabody MA, USA), which was firmly sealed and placed in $100 \mathrm{~mL}$ of $0.5 \%$ sodium dodecyl sulfate solution (the solubility of oleanolic acid in which was $318.42 \mu \mathrm{g} / \mathrm{mL}$ and conformed to sink condition) at $37^{\circ} \mathrm{C}$ with a rotating speed of $100 \mathrm{rpm}$. At predetermined intervals, $0.5 \mathrm{~mL}$ of release sample was withdrawn and the same volume of fresh release medium was replenished. The release characteristics of oleanolic acid from the SMEDDS was compared with oleanolic acid solution containing the same amount of drug dissolved in $0.5 \%$ sodium dodecyl sulfate solution. The samples were analyzed by HPLC. Release percentages were calculated as the ratio of the amount of drug released to the total initial amount of drug in the dialysis bag.

\section{Determination of oleanolic acid in rat plasma by HPLC-mass spectrometry}

In this study, HPLC-mass spectrometry was used to determine the concentration of oleanolic acid in rat plasma. The HPLC-mass spectrometry system comprised an Agilent 
1100 series instrument (Agilent Technologies, Santa Clara, CA, USA) coupled with an API 4000 mass spectrometer (Applied Biosystems, Foster City, California, USA). Oleanolic acid was separated using an ODS analytical column (150 mm $\times 2.1 \mathrm{~mm}$ ID, $5.0 \mu \mathrm{m}$, Phenomenex) guarded with a refillable precolumn $(\mathrm{C} 18,20 \mathrm{~mm} \times 2.0 \mathrm{~mm}$, Alltech Corporation, Staten Island, NY, USA). The mobile phase was composed of acetonitrile and $20 \mathrm{mM}$ ammonium acetate solution at a volume ratio of $85: 15$. The mobile phase was pumped at a flow rate of $0.5 \mathrm{~mL}$ per minute. The mass spectrometer was operated in negative ion detection mode with the spray voltage at $40 \mathrm{~V}$. The pressure of atomization gas, curtain gas, and auxiliary gas was set at $30 \mathrm{~V}, 15 \mathrm{~V}$, and $25 \mathrm{~V}$, respectively. The heated capillary temperature was set at $500^{\circ} \mathrm{C}$. The energy of collision was $24 \mathrm{~V}$. Quantification was performed using selective ion monitoring of $\mathrm{m} / \mathrm{z} 455.2 \rightarrow 455.4$ for oleanolic acid and $\mathrm{m} / \mathrm{z} 312.0 \rightarrow 270.2$ for benorilate, which separated well from oleanolic acid.

Calibration standards were constructed using a series of plasma concentrations of $0.5,1,5,25,125,250$, and $500 \mathrm{ng} / \mathrm{mL}$ of oleanolic acid, respectively. The absolute recovery, intraday precision, and interday precision were evaluated at three concentration levels. The stability of plasma samples at $-40^{\circ} \mathrm{C}$ and during three freeze-thawing cycles was also evaluated.

\section{Bioavailability studies}

The bioavailability of the oleanolic acid-loaded SMEDDS was compared with that of the commercial tablets. Male Sprague Dawley rats were fasted overnight before this experiment with free access to water, and divided randomly into two groups, each containing five rats. The rats were given $5 \mathrm{~mL}$ of water after oral administration of oleanolic acid-loaded SMEDDS and tablets at a dose of $50 \mathrm{mg} / \mathrm{kg}$. Next, $0.5 \mathrm{~mL}$ blood samples were collected from the retro-orbital plexus into heparinized tubes at predetermined time points of 0 , $0.5,1,1.5,2,3,4,6,8,12,16,24$, and 36 hours. The blood samples were then centrifuged at $3000 \mathrm{rpm}$ for 10 minutes. Plasma samples were then withdrawn and stored at $-40^{\circ} \mathrm{C}$ until analysis.

\section{Results and discussion Solubility assay}

When preparing a SMEDDS formulation, it is important that steps be taken to avoid precipitation of the drug on dilution in gastrointestinal tract. Therefore, vehicles used in a SMEDDS should have high solubilization capacity to ensure complete dissolution of the drug. Table 1 shows that oleanolic acid dissolved efficiently in oleic acid and ethyl oleate (oil), Labrasol and Cremophor EL (surfactant), and alcohol (cosurfactant).

\section{Compatibility tests}

Oils and surfactants with good solubility do not always show good emulsifying capability, so it is critical to evaluate the compatibility of different oils and surfactants in an optimal design formulation. According to the results of compatibility tests (Table 2), the emulsifying capability of ethyl oleate was better than of other oils with different surfactants, so ethyl oleate was chosen as a suitable oil. Cremophor EL was the optimal surfactant, and showed the best emulsifying capability.

\section{Selection of cosurfactants}

Pseudoternary phase diagrams for the different formulations are shown in Figure 1. The shadow microemulsion region is presented in these phase diagrams. By comparing the area of microemulsion domains with different cosurfactants, alcohol was chosen as the optimal cosurfactant.

\section{Formulation optimization}

In the ternary phase diagram, the shadow area represents the self-microemulsion region, as shown in Figure 2. Based on our results, an optimal SMEDDS formulation was established as shown in Table 3, ie, 50\% ethyl oleate as the oil, $35 \%$ Cremophor EL as the surfactant, and 15\% alcohol as the cosurfactant. Solubility of oleanolic acid in the optimal formulation was determined as $13.196 \pm 0.328 \mathrm{mg} / \mathrm{g}$, which was a significant increase compared with the solubility of crude oleanolic acid $(4.61 \mu \mathrm{g} / \mathrm{mL})$.

\section{Physicochemical characterization of SMEDDS}

The results of transmission electron microscopic imaging are shown in Figure 3. The microemulsion droplets appeared as a perfect round shape without aggregation.

Table I Solubility of oleanolic acid in different vehicles $(\mathrm{mg} / \mathrm{g})$

\begin{tabular}{|c|c|c|c|}
\hline Vehicle & Solubility & Vehicle & Solubility \\
\hline Oleic acid & $5.40 \pm 0.07$ & Tween ${ }^{\circledR} 80$ & $5.54 \pm 0.20$ \\
\hline Ethyl oleate & $5.06 \pm 0.12$ & Cremophor EL ${ }^{\circledR}$ & $5.65 \pm 0.17$ \\
\hline Caprylic/Capric & $2.60 \pm 0.11$ & Alcohol & $9.84 \pm 0.09$ \\
\hline \multicolumn{4}{|l|}{ Triglyceride } \\
\hline Isopropyl myristate & $2.34 \pm 0.15$ & I,2-Propylene glycol & $1.94 \pm 0.14$ \\
\hline Labrasol $^{\circledR}$ & $8.08 \pm 0.15$ & Glycerol & $0.85 \pm 0.08$ \\
\hline $\begin{array}{l}\text { Polyoxyethylene } \\
\text { octylphenyl ether }\end{array}$ & $4.85 \pm 0.09$ & PEG 400 & $0.14 \pm 0.03$ \\
\hline
\end{tabular}

Abbreviation: PEG, polyethylene glycol. 
Table 2 Results of compatibility tests

\begin{tabular}{|c|c|c|c|c|}
\hline \multirow[t]{2}{*}{ Ratios } & \multicolumn{4}{|c|}{ Visual grading $^{\mathrm{a}}$} \\
\hline & $\begin{array}{l}\text { Oleic } \\
\text { acid }\end{array}$ & $\begin{array}{l}\text { Ethyl } \\
\text { oleate }\end{array}$ & $\begin{array}{l}\text { Caprylic/Capric } \\
\text { Triglyceride }\end{array}$ & $\begin{array}{l}\text { Isopropyl } \\
\text { myristate }\end{array}$ \\
\hline \multicolumn{5}{|c|}{ Labrasol $^{\circledR}$} \\
\hline $9: 1$ & $\mathrm{D}$ & C & $\mathrm{E}$ & $E$ \\
\hline $8: 2$ & $E$ & $\mathrm{D}$ & $E$ & $\mathrm{E}$ \\
\hline $7: 3$ & $E$ & $\mathrm{D}$ & $\mathrm{E}$ & $E$ \\
\hline \multicolumn{5}{|c|}{ Polyoxyethylene octylphenyl ether } \\
\hline $9: 1$ & C & $\mathrm{D}$ & $\mathrm{D}$ & $\mathrm{D}$ \\
\hline $8: 2$ & $\mathrm{D}$ & $\mathrm{E}$ & $\mathrm{E}$ & $E$ \\
\hline $7: 3$ & $\mathrm{D}$ & $\mathrm{E}$ & $\mathrm{E}$ & $\mathrm{E}$ \\
\hline \multicolumn{5}{|c|}{ Tween $^{\circledR} 80$} \\
\hline $9: 1$ & $\mathrm{C}$ & $A$ & $\mathrm{D}$ & B \\
\hline $8: 2$ & $\mathrm{D}$ & $A$ & $\mathrm{D}$ & B \\
\hline $7: 3$ & $\mathrm{D}$ & B & $E$ & C \\
\hline \multicolumn{5}{|c|}{ Cremophor $\mathrm{EL}^{\circledR}$} \\
\hline $9: 1$ & $\mathrm{C}$ & $A$ & $\mathrm{D}$ & $A$ \\
\hline $8: 2$ & $\mathrm{D}$ & $A$ & $\mathrm{D}$ & B \\
\hline $7: 3$ & $D$ & A & $D$ & B \\
\hline
\end{tabular}

Notes: ${ }^{a} A$, denotes a rapidly forming (within one minute) microemulsion which was clear or slightly bluish in appearance; B, denotes a rapidly forming, slightly less clear emulsion with a bluish white appearance; $\mathrm{C}$, denotes a bright white emulsion (similar in appearance to milk) that formed within 2 minutes; D, denotes a dull, grayish white emulsion with a slightly oily appearance that was slow to emulsify (longer than 2 minutes); $E$, denotes a formulation with either poor or minimal emulsification and large oil droplets present on the surface.

A

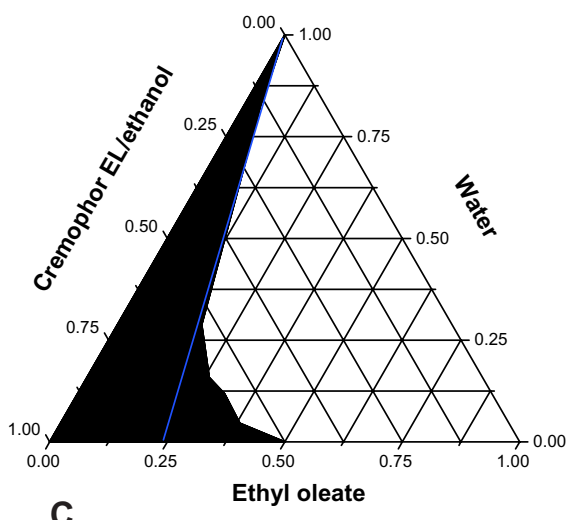

C

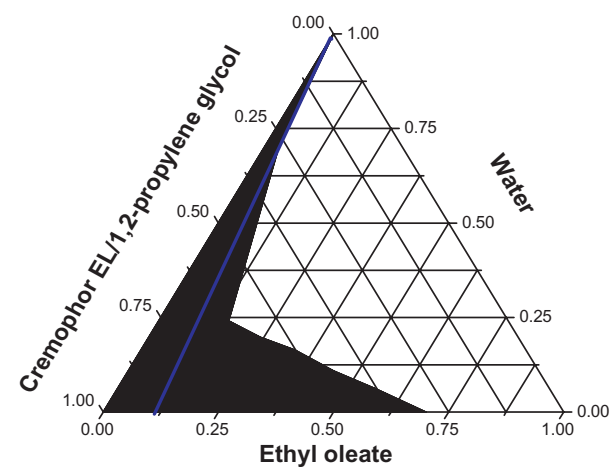

The size distribution of the oleanolic acid-loaded SMEDDS formulation is shown in Figure 4. Droplet size distribution is a critical factor when evaluating a SMEDDS, and it is known that droplet size has a significant effect on drug absorption in the gastrointestinal tract. The smaller the droplet size, the larger the interfacial surface area provided for drug absorption, and this has a strong relationship with oral bioavailability. ${ }^{24,28,29}$ The average droplet size in the microemulsion dispersed from the oleanolic acid-loaded SMEDDS was less than $100 \mathrm{~nm}$ and showed a Gaussian distribution. The effects of dilution on droplet size in distilled water were measured. When the SMEDDS was diluted 25, 100, 400 times, the droplet size seemed to be unchanged, indicating that the microemulsion structure remained stable when dilution was as large as 400 -fold. The effect of different types of dilution medium (dilution 100-fold) on droplet size was also investigated when the SMEDDS formulation was dispersed in distilled water, normal solution, $0.1 \mathrm{~mol} / \mathrm{L}$ hydrochloride solution, and phosphate-buffered saline (pH 6.8); the resulting droplet sizes were $53.1 \pm 4.2 \mathrm{~nm}$, $47.5 \pm 4.5 \mathrm{~nm}, 52.2 \pm 5.5 \mathrm{~nm}$, and $52.8 \pm 4.9 \mathrm{~nm}$, respectively.

B

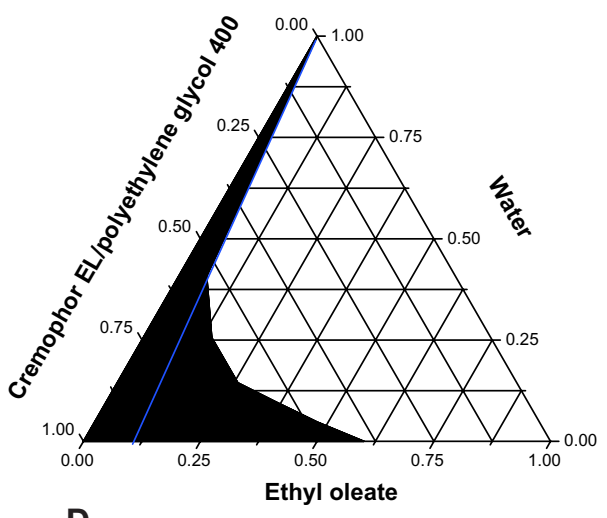

D

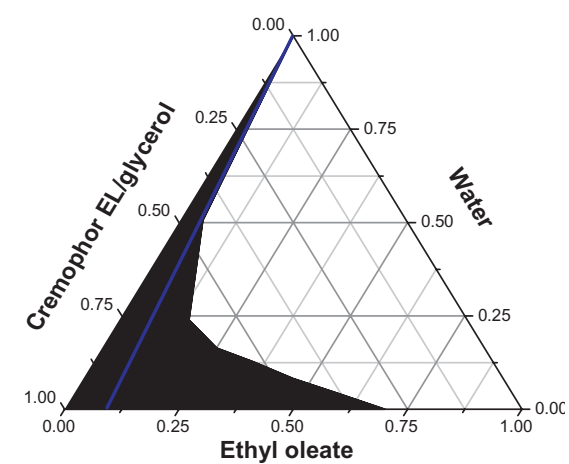

Figure I Pseudoternary phase diagrams for different cosurfactants. (A) Alcohol, (B) PEG 400, (C) I,2-propylene glycol, and (D) glycerol, with the shadow area representing the microemulsion region. Abbreviation: PEG, polyethylene glycol. 


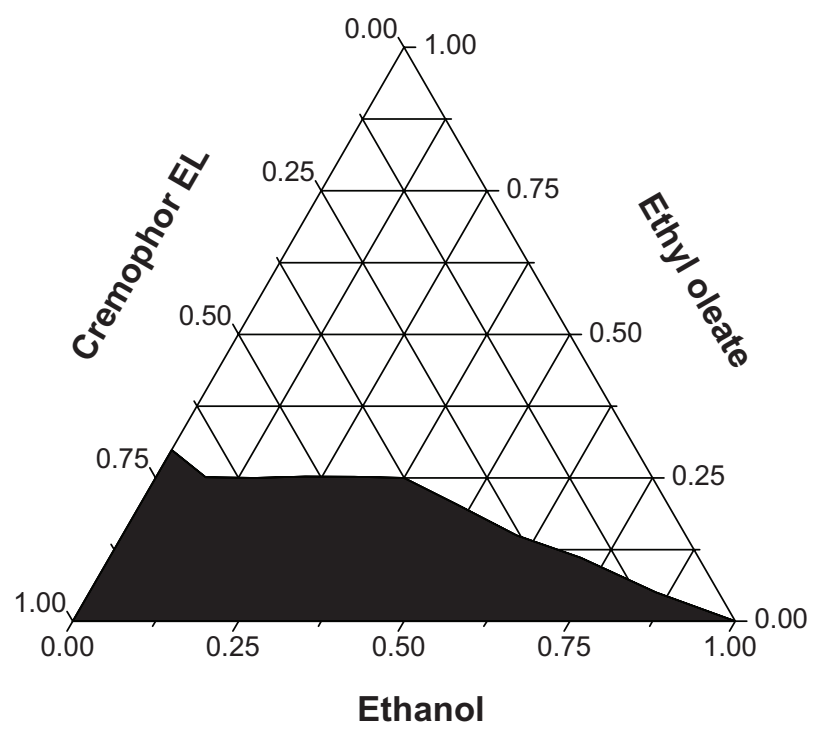

Figure 2 Ternary phase diagram for the self-microemulsifying drug delivery system, with the shadowed area representing the self-microemulsion regions.

There was no significant difference between the four types of dilution medium, indicating that the formulation was not affected by $\mathrm{pH}$ and ionic strength.

The physicochemical characteristics of the oleanolic acid-loaded SMEDDS formulation on 100-fold dilution with distilled water were as follows: $1.78 \pm 0.05 \mathrm{~mm}^{2} /$ $\mathrm{sec}$ for viscosity, $92.7 \pm 1.6 \mu \mathrm{sec} / \mathrm{cm}$ for electrical conductivity, and $1.396 \pm 0.004$ for refractive index, respectively.

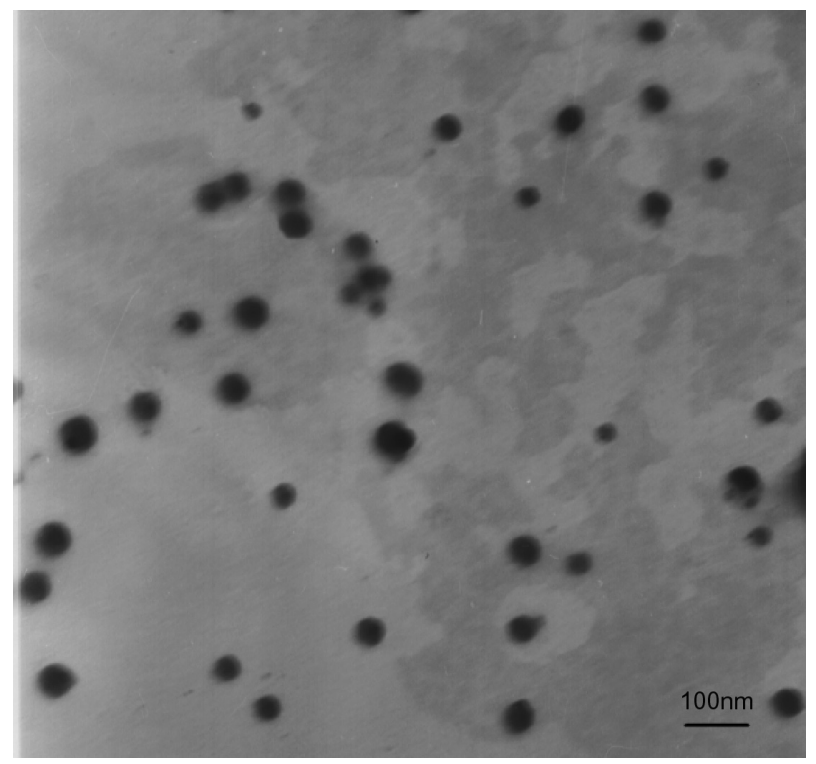

Figure 3 Transmission electron micrograph of the self-microemulsifying drug delivery system containing oleanolic acid $(\times 29,000$; dilution 100 -fold with water) with the black dots representing droplets of microemulsion.

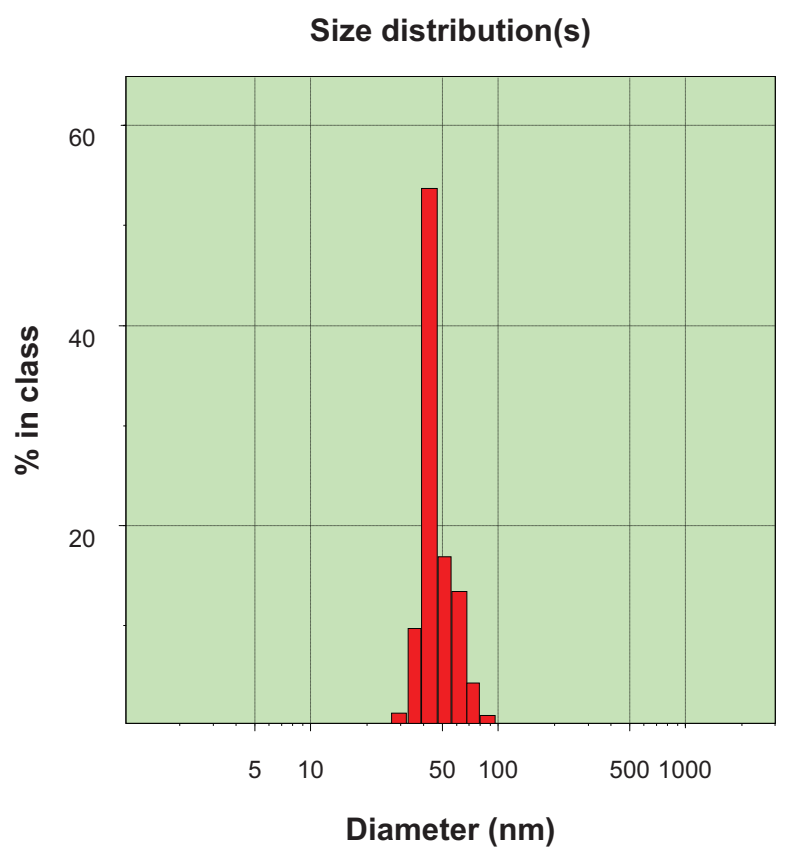

Figure 4 Size distribution of the oleanolic acid self-microemulsifying drug delivery system.

\section{In vitro release studies}

An in vitro release study was carried out to investigate the characteristics of release of oleanolic acid from the SMEDDS formulation. However, a conventional release protocol cannot be used for a SMEDDS, because free drug and microemulsionassociated drug are not able to be separated before analysis. At present, a dialysis method is used for in vitro study of drug release from a SMEDDS. ${ }^{26,30}$ Drug release profiles for the SMEDDS and control formulations are shown in Figure 5.

Our results indicate that release of oleanolic acid from both the SMEDDS formulation and the control solution followed Weibull kinetics, and the equations were

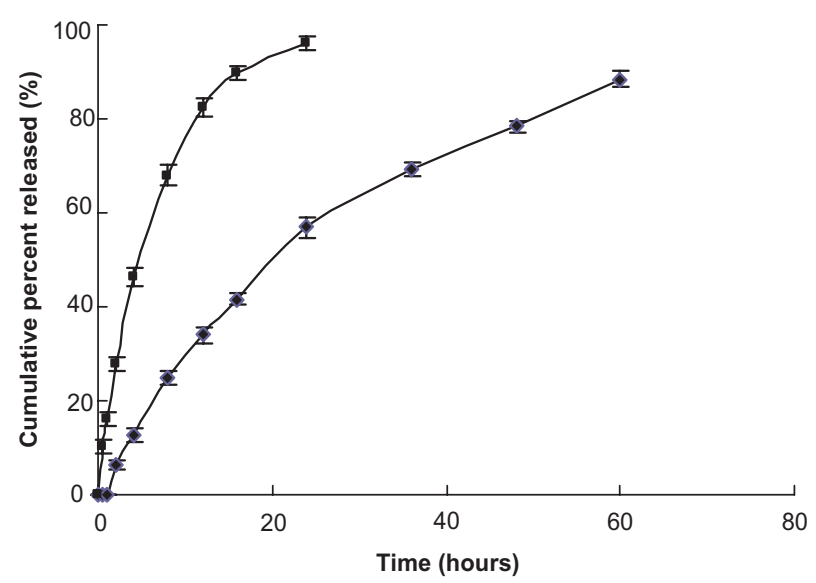

Figure $\mathbf{5}$ In vitro release profile for oleanolic acid from the self-microemulsifying drug delivery system $(\bullet)$ and solution $(\boldsymbol{\square})$. 
$\ln [-\ln (1-\mathrm{Q} \%)]=1.0034 \ln t-3.3897(r=0.9992)$ and $\ln [-$ $\ln (1-\mathrm{Q} \%)]=0.89632 \operatorname{lnt}-1.6963(r=0.9994)$, respectively. Compared with the control solution, oleanolic acid could be released in a sustained manner from the SMEDDS. It is suggested that oleanolic acid may exist in internal oil phase and the interfacial film of a microemulsion droplet, and that drug release may proceed via the route of internal oil phase to interfacial film to external water phase, which delays the release of oleanolic acid.

\section{A}
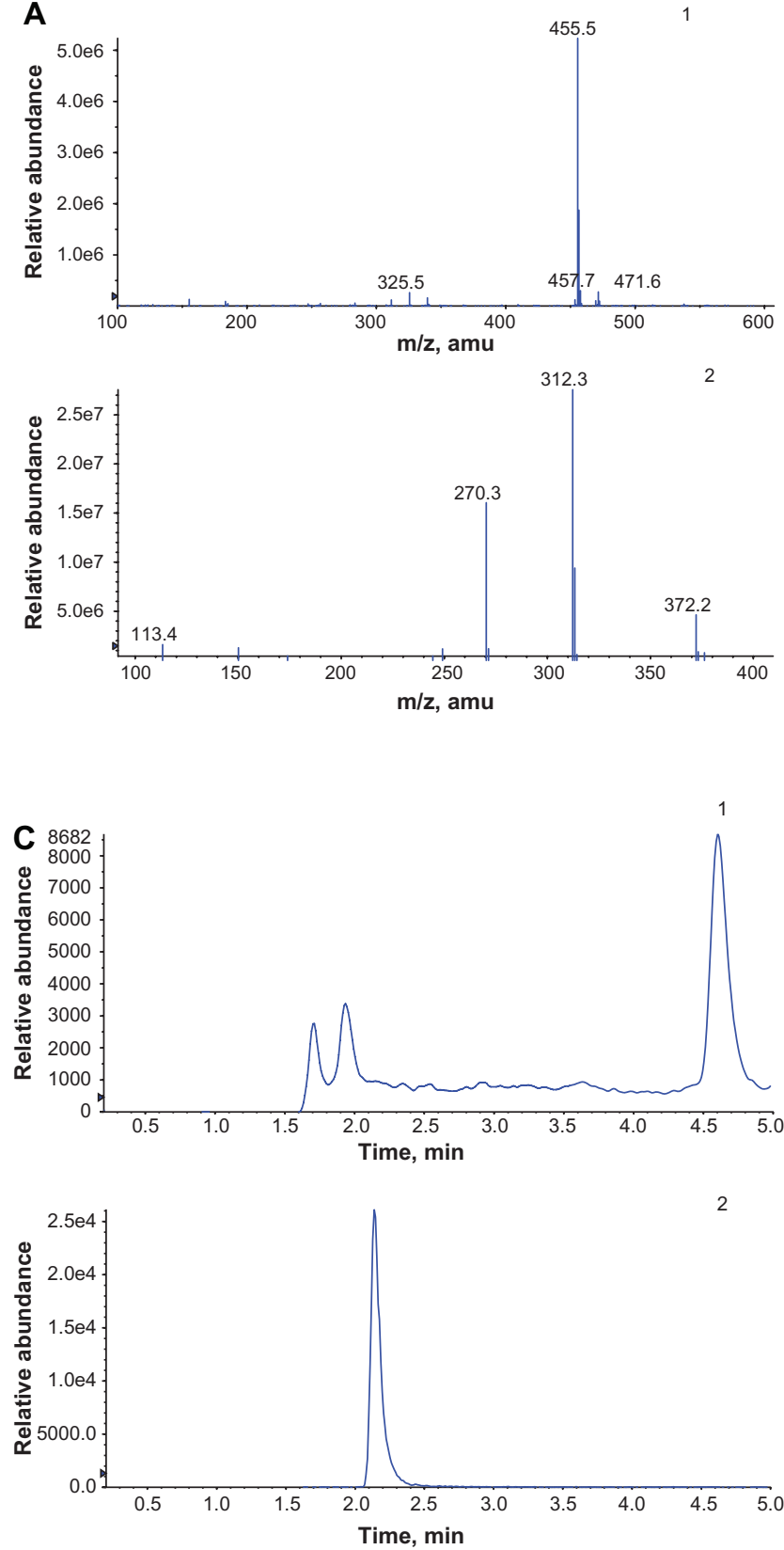

Determination of oleanolic acid in rat plasma by HPLC-mass spectrometry

Oleanolic acid and the internal standard were separated well from impurities in the plasma extracts, and the mass spectra and typical chromatograms (Figure 6) show a retention time of about 4.65 minutes and 2.13 minutes for oleanolic acid and the internal standard, respectively. In the concentration range of $0.5-500 \mathrm{ng} / \mathrm{mL}$, the peak area ratio $(\mathrm{R})$ of oleanolic acid to the internal standard correlated well with
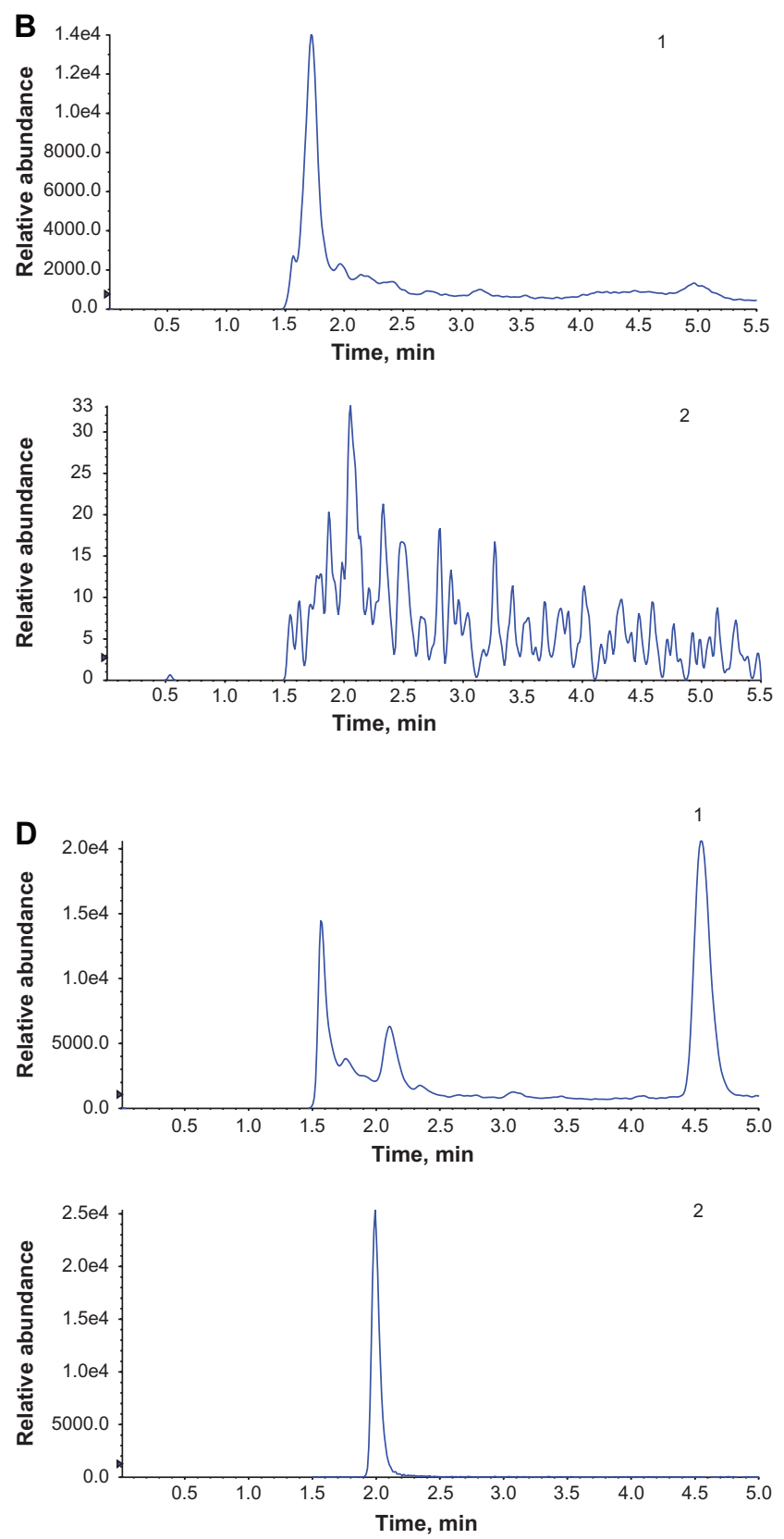

Figure 6 Mass spectra and chromatograms for plasma. (A) Mass spectra of oleanolic acid (A) and benorilate (B, internal standard); (B) is blank plasma; (C) is plasma added with $0.5 \mathrm{ng} / \mathrm{mL}$ oleanolic acid and $50 \mathrm{ng} / \mathrm{mL}$ benorilate; (D) is plasma sample after administration of the oleanolic acid-loaded self-microemulsifying drug delivery system. ( $\mathrm{l}$ represents oleanolic acid with $\mathrm{m} / \mathrm{z} 455.2 \rightarrow 455.4$, and 2 represents benorilate as internal standard with $\mathrm{m} / \mathrm{z} 3$ I 2.0 $\rightarrow 270.2$ ). 
plasma concentration, ie, $\mathrm{R}=14.259 \mathrm{C}-2.7683(r=0.9993)$. The absolute recovery, and intraday and interday precision for determination of oleanolic acid in rat plasma at 1.0,25.0, and $400 \mathrm{ng} / \mathrm{mL}$ levels are shown in Table 4 . The stability of oleanolic acid in plasma was tested by analysis of the control samples at 1.0, 25.0, and $400 \mathrm{ng} / \mathrm{mL}$ levels. It was found that oleanolic acid was stable in plasma at $-40^{\circ} \mathrm{C}$ for at least 30 days and during three freeze-thawing cycles.

\section{Bioavailability results}

The pharmacokinetic parameters for oleanolic acid-loaded SMEDDS and tablets were compared in rats. The mean plasma concentration-time curves for the oleanolic acidloaded SMEDDS formulation and the control tablets are shown in Figure 7. The major pharmacokinetic parameters for oleanolic acid in the SMEDDS and tablet formulations are shown in Table 5. As indicated, the maximum plasma concentration and area under the plasma concentration-time curve for oleanolic acid in SMEDDS was $209.80 \mathrm{ng} / \mathrm{mL}$ and $1740.06 \mathrm{ng} \mathrm{h} / \mathrm{mL}$, which is 2.71 -fold and 5.07 -fold that of the commercial tablet, respectively.

The relative bioavailability of oleanolic acid in SMEDDS was dramatically increased compared with the commercial oleanolic acid tablet. There may be several reasons for the high bioavailability of SMEDDS. First, SMEDDS can markedly increase the solubility of a lipid-soluble drug. For a poorly water-soluble drug, absorption is often inadequate due to insufficient dissolution in the gastrointestinal tract. Therefore, the dissolution process may be an important factor influencing absorption. The SMEDDS transforms into microemulsion in the gastrointestinal tract, which keeps the drug in a dissolved form, which is beneficial for enhanced absorption. Second, the SMEDDS forms a fine o/w microemulsion with

Table 3 Design and results of formulation optimization

\begin{tabular}{|c|c|c|c|c|c|}
\hline \multicolumn{4}{|c|}{ Formula composition \% } & \multirow{2}{*}{$\begin{array}{l}\text { Drug } \\
\text { content } \\
\text { (mg/g) }\end{array}$} & \multirow{2}{*}{$\begin{array}{l}\text { Droplet } \\
\text { size } \\
(\mathbf{n m})\end{array}$} \\
\hline Number & $\begin{array}{l}\text { Cremophor } \\
\text { EL }^{\circledR}\end{array}$ & Alcohol & $\begin{array}{l}\text { Ethyl } \\
\text { oleate }\end{array}$ & & \\
\hline I & 80 & 5 & 15 & $6.955 \pm 0.187$ & 69 \\
\hline 2 & 75 & 10 & 15 & $8.130 \pm 0.198$ & 65.4 \\
\hline 3 & 70 & 15 & 15 & $9.392 \pm 0.154$ & 62.8 \\
\hline 4 & 65 & 20 & 15 & $10.427 \pm 0.197$ & 60.3 \\
\hline 5 & 60 & 25 & 15 & $11.610 \pm 0.266$ & 57.7 \\
\hline 6 & 55 & 30 & 15 & $12.330 \pm 0.262$ & 53.2 \\
\hline 7 & 50 & 35 & 15 & $13.196 \pm 0.328$ & 49.7 \\
\hline 8 & 45 & 40 & 15 & $|3.333 \pm 0.35|$ & 53.2 \\
\hline 9 & 40 & 45 & 15 & $|3.570 \pm 0.31|$ & 55.7 \\
\hline 10 & 35 & 50 & 15 & $14.087 \pm 0.463$ & 59.2 \\
\hline II & 30 & 55 & 15 & $14.022 \pm 0.402$ & 64.8 \\
\hline
\end{tabular}

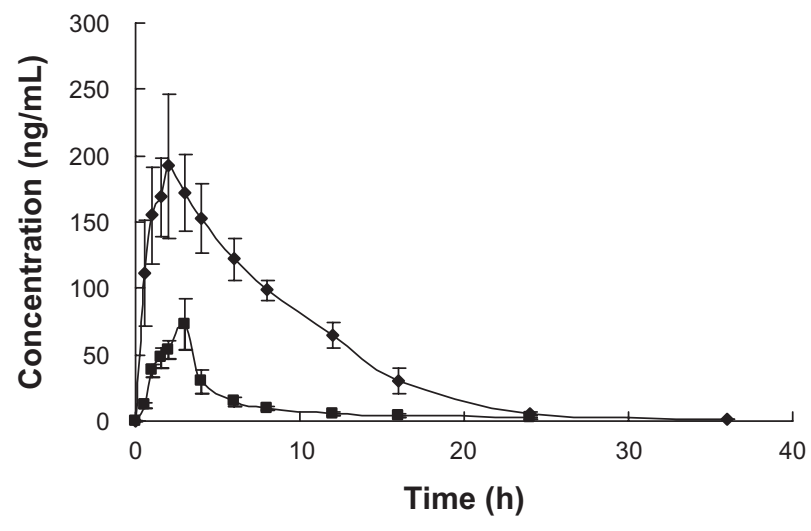

Figure 7 Mean plasma concentration-time profile following oral administration of oleanolic acid-loaded self-microemulsifying drug delivery system $(\downarrow)$ and commercial tablet $(\mathbf{\square})$ in rats.

a droplet size of less than $100 \mathrm{~nm}$ when it emerges in the gastrointestinal tract. The small droplet size provides a large interfacial surface area for the drug to come into contact with the cell membrane, which might increase drug release and absorption. Third, the high surfactant content in a SMEDDS may increase permeability by disturbing the cell membrane. ${ }^{30}$ Drug absorption mechanisms may include the transcellular and paracellular routes, and hydrophobic drugs with a low molecular weight, such as oleanolic acid, are absorbed transcellularly in most cases. The main barrier to their absorption is considered to be the tight junctions of cells. The surfactant in SMEDDS can reduce the interfacial surface tension and enhance penetration of the drug into epithelial cells. ${ }^{24}$ The structural characteristics of surfactant allow it to partition between lipid and protein domains. ${ }^{30}$ Surfactant can interact with the polar head groups in the lipid bilayers, and modify hydrogen bonding and ionic forces. It may also insert between the lipophilic tails of the lipid bilayers, which could disrupt the lipid-packing arrangement. Eventually, the inclusion of a lipid in a SMEDDS formulation may stimulate formation of lipoproteins and chylomicrons, subsequently promoting the lymphatic pathway for drug absorption, which may reduce the opportunity for hepatic first-pass metabolism and thereby enhance oral drug bioavailability, which has been confirmed by Hauss et al. ${ }^{31}$

Table 4 Absolute recovery, precision $(n=5)$ of the assay method

\begin{tabular}{llllll}
\hline $\begin{array}{l}\text { Concentration } \\
(\mathbf{n g} / \mathbf{m L})\end{array}$ & \multicolumn{2}{l}{ Absolute recovery } & & \multicolumn{2}{l}{ Precision, RSD (\%) } \\
\cline { 2 - 3 } & Mean $(\%)$ & RSD $(\%)$ & & Intraday & Interday \\
\hline 1.0 & 35.28 & 4.62 & & 2.66 & 3.07 \\
25.0 & 34.68 & 2.20 & & 2.51 & 3.32 \\
400.0 & 36.60 & 3.03 & & 2.08 & 2.62 \\
\hline
\end{tabular}

Abbreviation: RSD, relative standard deviation. 
Table 5 Major pharmacokinetic parameters of oleanolic acid after oral administration of oleanolic acid-loaded SMEDDS and a commercial tablet in rats

\begin{tabular}{lcc}
\hline & SMEDDS & Tablet \\
\hline $\mathrm{AUC}_{0 \rightarrow \mathrm{t}}(\mathrm{ng} \mathrm{h} / \mathrm{mL})$ & $1740.06 \pm 163.25$ & $308.19 \pm 55.04$ \\
$\mathrm{AUC}_{0 \rightarrow \infty}(\mathrm{ng} \mathrm{h} / \mathrm{mL})$ & $1775.26 \pm 157.9 \mathrm{I}$ & $350.13 \pm 73.67$ \\
$\mathrm{C}_{\max }(\mathrm{ng} / \mathrm{mL})$ & $209.80 \pm 47.19$ & $77.60 \pm 16.79$ \\
$\mathrm{~T}_{\text {max }}$ (hours) & $2.00 \pm 1.00$ & $2.75 \pm 0.50$ \\
Relative bioavailability (\%) & $507.03 \%$ & \\
\hline
\end{tabular}

Abbreviations: $A U C$, area under the curve; $C_{\max }$, peak plasma concentration; $\mathrm{T}_{\max }$, time to peak plasma concentration; SMEDDS, self-microemulsifying drug delivery system.

\section{Conclusion}

A SMEDDS formulation was developed, in which the optimal ratio of ethyl oleate to Cremophor EL to alcohol in the formulation was 50:35:15 (w/w). When diluted with water, the oleanolic acid-loaded SMEDDS could spontaneously form small particles. Neither dilution volume nor type of dilution medium had a significant effect on particle size or self-microemulsifying behavior. In vitro release of oleanolic acid from SMEDDS determined using a dialysis method showed typical sustained-release characteristics. The plasma concentration of oleanolic acid in the rat was determined by HPLC-mass spectrometry. The results of a pharmacokinetic study showed that the relative bioavailability of oleanolic acid was markedly improved, being approximately $507 \%$ that of the oleanolic acid tablet. This study provides evidence that a SMEDDS is valuable for oral delivery of oleanolic acid, and could potentially be used to enhance the oral absorption of poorly water-soluble drugs.

\section{Acknowledgment}

This work was supported partly by a research grant (2006GG2202053) from Department of Shandong Science and Technology, People's Republic of China.

\section{Disclosure}

The authors report no conflicts of interest in this work.

\section{References}

1. Mahato SB, Garai S. Triterpenoid saponins. Fortschr Chem Org Naturst. 1998;74:1-196.

2. Wang B, Jiang ZH. Studies on oleanolic acid. Chin Pharm J. 1992;27: 393-397.

3. Price KR, Johnson IT, Fenwick GR. The chemistry and biological significance of saponins in foods and feedingstuffs. Crit Rev Food Sci Nutr. 1987;26:27-135.

4. Liu J. Pharmacology of oleanolic acid and ursolic acid. JEthnopharmacol. 1995;49:57-68.

5. Xi J, Chang Q, Chan CK, et al. Formulation development and bioavailability evaluation of a self-nanoemulsified drug delivery system of oleanolic acid. AAPS PharmSciTech. 2009;10:172-182.
6. Pollier J, Goossens A. Oleanolic acid. Phytochemistry. 2012;77:10-15.

7. Somova LI, Shode FO, Ramnanan P, Nadar A. Antihypertensive, antiatherosclerotic and antioxidant activity of triterpenoids isolated from Olea europaea, subspecies africana leaves. J Ethnopharmacol. 2003;84:299-305.

8. Assimopoulou AN, Zlatanos SN, Papageorgiou VP. Antioxidant activity of natural resins and bioactive triterpenes in oil substrates. Food Chem. 2005;92:721-727.

9. Somova LI, Shode FO, Mipando M. Cardiotonic and antidysrhythmic effects of oleanolic and ursolic acids, methyl maslinate and uvaol. Phytomedicine. 2004;11:121-129.

10. Raphael TJ, Kuttan G. Effect of naturally occurring triterpenoids glycyrrhizic acid, ursolic acid, oleanolic acid and nomilin on the immune system. Phytomedicine. 2003;10:483-489.

11. Ali MS, Jahangir M, Hussan SS, Choudhary MI. Inhibition of alpha-glucosidase by oleanolic acid and its synthetic derivatives. Phytochemistry. 2002;60:295-299.

12. Kim KA, Lee JS, Park HJ, et al. Inhibition of cytochrome P450 activities by oleanolic acid and ursolic acid in human liver microsomes. Life Sci. 2004;74:2769-2779.

13. Oguro T, Liu J, Klaassen CD, Yoshida T. Inhibitory effect of oleanolic acid on 12-O-tetradecanoylphorbol-13-acetate-induced gene expression in mouse skin. Toxicol Sci. 1998;45:88-93.

14. Jager S, Winkler K, Pfuller U, Scheffler A. Solubility studies of oleanolic acid and betulinic acid in aqueous solutions and plant extracts of Viscum album L. Planta Med. 2007;73:157-162.

15. Jager S, Laszczyk MN, Scheffler A. A preliminary pharmacokinetic study of betulin, the main pentacyclic triterpene from extract of outer bark of birch (Betulae alba cortex). Molecules. 2008;13: 3224-3235.

16. Jin IJ, Ko YI, Kim YM, Han SK. Solubilization of oleanolic acid and ursolic acid by cosolvency. Arch Pharm Res. 1997;20:269-274.

17. Jeong DW, Kim YH, Kim HH, et al. Dose-linear pharmacokinetics of oleanolic acid after intravenous and oral administration in rats. Biopharm Drug Dispos. 2007;28:51-57.

18. Chen Y, Liu J, Yang X, Zhao X, Xu H. Oleanolic acid nanosuspensions: preparation, in-vitro characterization and enhanced hepatoprotective effect. J Pharm Pharmacol. 2005;57:259-264.

19. Liu L, Wang X. Improved dissolution of oleanolic acid with ternary solid dispersions. AAPS PharmSciTech. 2007;8:E113.

20. Constantinides PP. Lipid microemulsions for improving drug dissolution and oral absorption: physical and biopharmaceutical aspects. Pharm Res. 1995;12:1561-1572.

21. Shah NH, Carvajal MT, Patel CI, Infeld NH, Malick AW. Selfemulsifying drug delivery systems (SEDDS) with polyglycolized glycerides for improving in vitro dissolution and oral absorption of lipophilic drugs. Int J Pharm. 1994;106:15-23.

22. Iwanaga K, Kushibiki T, Miyazaki M, Kakemi M. Disposition of lipidbased formulation in the intestinal tract affects the absorption of poorly water-soluble drugs. Biol Pharm Bull. 2006;29:508-512.

23. Porter CJ, Trevaskis NL, Charman WN. Lipids and lipid-based formulations: optimizing the oral delivery of lipophilic drugs. Nat Rev Drug Discov. 2007;6:231-248.

24. Zhang P, Liu Y, Feng N, Xu J. Preparation and evaluation of selfmicroemulsifying drug delivery system of oridonin. Int $J$ Pharm. 2008;355:269-276.

25. Kang BK, Lee JS, Chon SK, et al. Development of selfmicroemulsifying drug delivery systems (SMEDDS) for oral bioavailability enhancement of simvastatin in beagle dogs. Int J Pharm. 2004;274:65-73.

26. Wu W, Wang Y, Que L. Enhanced bioavailability of silymarin by self-microemulsifying drug delivery system. EurJ Pharm Biopharm. 2006;63:288-294.

27. Khoo SM, Humberstone AJ, Porter JHC, Edwards GA, Charman WN. Formulation design and bioavailability assessment of lipidic selfemulsifying formulations of halofantrine. Int J Pharm. 1998;167: $155-164$. 
28. Surjyanarayan M, Snigdha MS, Naazneen S, Vandana PB, Mandal PAS. Design and development of saquinavir microemulsion for the oral bioavailability enhancement. Int J Pharm Tech Res. 2009;1:1442-1448.

29. Patel AR, Vavia PR. Preparation and in vivo evaluation of SMEDDS (self-microemulsifying drug delivery system) containing fenofibrate. AAPS J. 2007;9:E344-E352.
30. Swenson ES, Curatolo WJ. Means to enhance penetration. Adv Drug Deliv Rev. 1992;8:39-42.

31. Hauss DJ, Mehta SC, Radebaugh GW. Targeted lymphatic transport and modified systemic distribution of CI-976, a lipophilic lipid-regulator drug, via a formulation approach. Int J Pharm. 1994;108:85-93.

\section{Publish your work in this journal}

The International Journal of Nanomedicine is an international, peerreviewed journal focusing on the application of nanotechnology in diagnostics, therapeutics, and drug delivery systems throughout the biomedical field. This journal is indexed on PubMed Central, MedLine, CAS, SciSearch $\AA$, Current Contents ${ }^{\circledR} /$ Clinical Medicine,
Journal Citation Reports/Science Edition, EMBase, Scopus and the Elsevier Bibliographic databases. The manuscript management system is completely online and includes a very quick and fair peer-review system, which is all easy to use. Visit http://www.dovepress.com/ testimonials.php to read real quotes from published authors. 